\title{
JUURNAL.RU
}

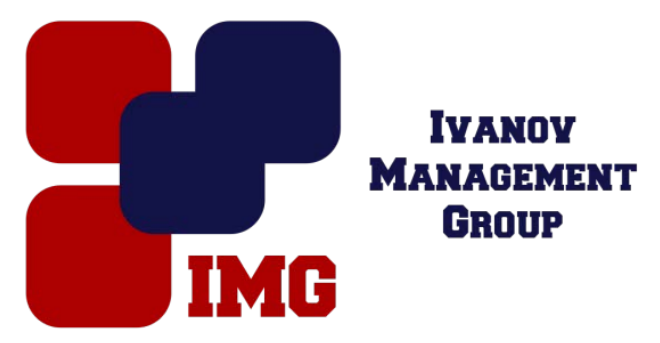

Беспалов Е.С., Болтов М.С., Кривошей В.П. Донской Государственный Технический Университет Ростов-на-Дону, Россия

doi: 10.18411/lj-28-02-2017-1-11

idsp 000001:lj-28-02-2017-1-11

\section{Программно-информационные системы кафедры}

\section{Аннотация}

В данной работе можно ознакомиться с несколькими вариантами осуществления нахождения информации: соподчиненная структура и при помощи глобального поиска

Ключевые слова: соподчиненная структура, глобальный поиск

В наши дни компьютер является мощным инструментом, который обеспечивает моментальный доступ к любой информации по любой проблеме, которую можно решить. На протяжении нескольких лет обучения специалиста появляется решение такой задачи, как организации доступа информации, которая имеется на кафедре в виде научных и технических данных.

В процессе обучения различают некоторые задачи: нахождение решений, которые связанные с данной проблемой, изучение данных, которые взаимосвязанные между собой на разных дисциплинах. Анализируя научные технические данные кафедры, можно определить структурные блоки информационные источники: курсовые и дипломные проекты выпускников кафедры, наличие журналов по автоматике, публикации которые имеются в разных информационных источниках, технические справочники по автоматизации, научно-исследовательские работы преподавателей кафедры.

Самый верхний уровень информационной системы представляет собой наличие баз данных, которые были созданы в MicrosoftAccess. На нижнем уровне содержится информация в виде отдельных документов, дипломов и т.д., которые содержатся в электронном виде. Любой пользователь имеет право воспользоваться этими данными, а также он может вносить туда некоторые дополнения или изменения. Работа такой системы поддерживается администратором. В его обязанности входит не только поддержка работы системы, он может изменить структуризацию такой базы данных. В ходе работы он ежедневно рассматривает данные, которые были внесены пользователями и принимает решение: стоит ли 
включать такую информацию в базу данных. Вход в такую систему в качестве администратора происходит по паролю. Любой человек может войти в систему двумя способами: через соподчиненную структуру и при помощи глобального поиска. Рассмотрим первый способ. Пользователь сначала выбирает информационный ресурс, с которым он желает ознакомиться. В дальнейшем, он двигается на определенный раздел выбранного ресурса и ищет нужную информацию внутри данного раздела. Данный способ удобен тем, что пользователь заранее знает, какую информацию надо искать. Есть и другой метод нахождения данных - тогда поможет глобальный поиск. При помощи данного метода поиска информации следует задать нужную фразу, а также стоит выбрать определенный тип ресурса, где стоит производить поиск. В результате такого процесса человеку будут представлены различные варианты ресурсов, где встречается нужная фраза.

Создание такой системы стандартной программой MicrosoftAccess помогла реализовать доступ к данным, которые находятся на большом расстоянии от пользователя. Появление информационной системы в учебном процессе позволяет сделать быстрый доступ пользователей к различным данным, которые находятся на кафедре; производить ежедневное обновление и дополнение базы данных, которое способствует накоплению знаний у студентов и применению их на практике в течение учебного процесса в университете.

\section{Литература}

1. Эпштейн В.П. "Гипертекстовая база знаний теории управления" // Автоматика и телемеханика 2000 №11. 